\title{
AMALAN PERARAKAN USUNGAN DALAM MASYARAKAT PESISIRAN SARAWAK
}

\section{THE PARADE OF THE USUNGAN PRACTICES IN SARAWAK COASTAL COMMUNITY}

\section{Mohamad Faizuan Mat}

Faculty of Applied \& Creative Arts, Universiti Malaysia Sarawak, Sarawak, MALAYSIA

Email: mmfaizuan@unimas.my

Published online: 30 April 2021

To cite this article: Mohamad Faizuan Mat. 2021. Amalan perarakan usungan dalam masyarakat pesisiran Sarawak. Kajian Malaysia 39(1): 141-164. https://doi.org/10.21315/km2021.39.1.7

To link to this article: https://doi.org/10.21315/km2021.39.1.7

\begin{abstract}
The parade of the "usungan/tandu" is a unique traditional practice and is still performed by coastal communities of Sarawak. A parade is locally known as the "usungan/tandu" which is usually performed at the "khatam" al-Quran event. It is a tradition to celebrate the success of their children who have just completed the Holy al-Quran recitation. However, this tradition is practiced only in a few areas among the local coastal communities namely Kabong, Belawai, Bintulu, Mukah and Dalat that are actively practicing it up to this day. The practice which involves traditional skills is at risk of dying out. The privilege of this practice is not merely on the practical side, but it also has a high visual aesthetic value. The methods used in this study are interviews, observations and co-creation to assist the community in designing the "usungan/tandu". The "usungan/tandu" is designed according to the wishes and demands of children who are participating in the parade. The subject-matters of the design are inspired by the aesthetic qualities of aircraft, cars, houses, mosques, boats, flowers and fishes. The qualities of the "usungan/tandu" provide excitement and overall feeling of the artwork. It is alarming that this practice has been forgotten and most of the coastal area communities do not practice it anymore. In fact, there is no precise and accurate record or documentation done previously for references. Therefore, the purpose
\end{abstract}


of this study is to illustrate the "usungan/tandu" practices and to describe some of the embodiments that have been recorded for future references, and also to explain the uniqueness of "usungan/tandu" practices.

Keywords: usungan/tandu, palanquin, Sarawak coastal community, khatam of the al-Quran, local practices

\begin{abstract}
ABSTRAK
Amalan perarakan usungan/tandu merupakan suatu tradisi unik yang masih lagi diamalkan oleh masyarakat pesisir Sarawak. Perarakan yang dikenali sebagai usungan/tandu oleh masyarakat tempatan ini dijalankan semasa majlis khatam al-Quran. Ia merupakan tradisi untuk meraikan kejayaan anak-anak mereka yang baharu sahaja menamatkan pengajian kitab suci al-Quran. Walau bagaimanapun, tradisi ini hanya dijalankan di beberapa kawasan pesisir seperti daerah Kabong, Belawai, Bintulu, Mukah dan Dalat yang masih lagi aktif mengamalkannya hingga ke hari ini. Amalan yang melibatkan kemahiran tradisi yang tinggi ini kini berada di ambang kepupusan. Keistimewaan amalan ini bukan hanya terletak kepada praktisnya, bahkan ia juga mempunyai nilai estetika visual yang tinggi. Kaedah yang digunakan dalam kajian ini ialah temu bual, pemerhatian dan cipta-sama bagi membantu komuniti dalam penghasilan rekaan usungan/tandu. Usungan/tandu direka mengikut keinginan dan permintaan anak-anak yang menyertai perarakan ini. Antara bahan yang dijadikan inspirasi kepada rekaan tersebut ialah pesawat, kereta, rumah, masjid, perahu, bunga dan ikan. Keistimewaan usungan/tandu ini memberikan keseronokan dan perasaan yang menyeluruh terhadap karya seni. Perkara ini agak membimbangkan kerana amalan ini semakin dilupakan dan kebanyakan kawasan pesisir tidak mengamalkannya lagi. Bahkan tiada rekod atau dokumentasi yang lengkap dan tepat dilakukan sebelum ini untuk rujukan. Oleh itu, tujuan makalah ini dihasilkan adalah untuk memberi gambaran tentang amalan usungan/tandu dan memaparkan beberapa rekaan usungan/tandu yang telah direkodkan bagi tujuan rujukan pada masa akan datang serta penjelasan tentang amalan unik ini.
\end{abstract}

Kata kunci: usungan/tandu, komuniti pesisir Sarawak, khatam al-Quran, amalan tempatan 


\section{PENDAHULUAN}

Sarawak mempunyai kepelbagaian kaum dan etnik. Kepelbagaian ini membawa kepada kekayaan adat, budaya dan tradisi. Sering kali apabila disebut tentang Sarawak, etnik majoriti seperti Iban membayangkan kita kepada upacara Gawai Hantu. Perkara ini menunjukkan keunikan dan kekayaan yang ada pada Sarawak. Sarawak tidak hanya kaya dengan amalan dan tradisi kaum Dayak bahkan masyarakat Melayu di Sarawak juga tidak ketinggalan dan mempunyai adat serta amalannya yang tersendiri. Walau bagaimanapun, amalan dan tradisi masyarakat Melayu ini tidak mendapat perhatian dan diuar-uarkan kepada umum dengan sewajarnya. Aspek ini perlu diteroka dan dikaji untuk mewujudkan dokumentasi serta mengetengahkannya agar tidak hilang ditelan zaman. Di Sarawak khususnya, terdapat komuniti pesisir yang terdiri daripada masyarakat Melayu yang beragama Islam. Komuniti pesisir ini terdiri daripada beberapa daerah seperti Kota Samarahan, Asa Jaya, Sadong Jaya, Sebangan, Sebuyau, Triso, Meludam, Beladin, Pusa, Kabong, Tanjung Manis, Mukah, Dalat dan banyak lagi. Komuniti pesisir ini mempunyai adat dan budaya tersendiri dalam meraikan pencapaian dan kejayaan anak-anak mereka. Sudah menjadi amalan, majlis khatam al-Quran akan diadakan apabila anak-anak masyarakat pesisir ini menamatkan pengajian al-Quran dan perarakan usungan/tandu turut dijalankan. Merujuk Kamus Pelajar Edisi Kedua, usungan merupakan alat untuk mengusung atau benda yang diusung. Manakala tandu pula ialah alat yang berupa kerusi untuk mengusung orang. Masyarakat pesisir di daerah Kabong biasanya menggunakan perkataan usungan untuk perarakan tersebut. Manakala daerah Mukah dan Dalat lebih biasa memanggil tandu. Usungan/tandu ini merupakan alat yang sama namun berbeza panggilannya mengikut masyarakat tertentu. Objektif amalan ini diadakan adalah untuk meraikan anak-anak yang telah menamatkan pengajian al-Quran dan sebagai hadiah atas pencapaian mereka. Mereka akan diusung di atas usungan/ tandu mengelilingi kampung sebagai pemberi motivasi kepada kanak-kanak lain yang belum menamatkan pengajian al-Quran mereka. Usungan/tandu ini direka menggunakan pelbagai bentuk seperti kapal terbang, kereta, rumah, perahu, bot dan lain-lain lagi mengikut kehendak anak-anak itu sendiri atau keinginan ibu bapa mereka.

Usungan/tandu pada asalnya merupakan salah satu pengangkutan yang digunakan oleh manusia pada zaman dahulu. Sejarah penggunaan usungan/tandu ini rataratanya ada di setiap negara. Sebagai contoh, China sudah mula menggunakannya seawal tahun 1853. Manakala Turki, Filipina, Brazil dan lain-lain negara menggunakannya sebagai pengangkutan untuk mengangkat barangan mahupun manusia. Usungan/tandu merupakan alat berupa kerusi untuk mengusung orang bagi tujuan mengusung orang sakit, orang yang cedera dan lain-lain. Bertandu 
membawa maksud diusung dengan tandu atau menaiki tandu. Kebiasaannya usungan/tandu dibuat untuk tujuan memuliakan sultan. Dalam sejarah negeri Pahang contohnya, penggunaan tandu diamalkan untuk mengelakkan sultan daripada berjalan kaki ketika membuat lawatan dan sungai pula merupakan jalan perhubungan utama di Pahang suatu ketika dahulu. Pada zaman pemerintahan Sultan Ahmad al-Mu'adzam Shah, baginda menggunakan perahu atau kenderaan air untuk melawat sama ada ke hulu Pahang atau tempat lain. Oleh itu, penghulu di sesuatu kampung yang hendak dilawati akan menyediakan tandu sebagai kenaikan diraja melawat kampung mereka disebabkan ketiadaan kemudahan jalan raya yang baik dan kenderaan beroda seperti sekarang. Pembawa tandu terdiri di antara dua hingga enam orang. Namun, penggunaan tandu di Pahang hanya terkenal sehingga zaman pemerintahan Sultan Abdullah al-Mu'tassim Billah (1917-1932 TM) sahaja. Hal ini disebabkan tiada lagi penggunaan tandu semasa zaman pemerintahan Sultan Abu Bakar Ri'ayatuddin al-Mu'adzam Shah (1932-1974 TM).

Walau bagaimanapun, amalan ini sudah tidak lagi diamalkan kerana arus pemodenan dan kebanyakan komuniti atau masyarakat tidak terdedah dengan amalan ini. Namun begitu, kegunaan usungan/tandu telah berubah dengan merujuk kepada komuniti pesisir Sarawak iaitu masyarakat biasa juga boleh menggunakan usungan/tandu dalam pelbagai upacara. Pada suatu ketika dahulu, usungan/tandu digunakan untuk mengarak pengantin yang duduk di atasnya, dan pada zaman sekarang pengubahsuaian dilakukan dengan meletakkan kerusi yang dihias indah di atas usungan/tandu. Di samping itu, peralatan pengantin seperti sirih junjung, pulut kuning dan peralatan perkahwinan juga diletakkan di atas usungan/tandu tersebut.

Di persisiran pantai Sarawak seperti Belawai dan Kabong, amalan usungan/ tandu ini bukan sahaja meliputi perarakan untuk majlis perkahwinan tetapi untuk memuliakan peserta-peserta yang baharu menamatkan pengajian al-Quran. Majlis khatam al-Quran diadakan dan diiringi dengan perarakan usungan/tandu. Para peserta terdiri daripada kanak-kanak sekolah rendah yang berumur 7 hingga 12 tahun. Ia merupakan suatu praktis dan amalan turun-temurun yang dijalankan sejak sekian lama. Pelbagai bentuk replika dibina sebagai alat usungan untuk kegunaan peserta khatam al-Quran yang kemudiannya akan diarak di sepanjang jalan utama untuk menguar-uarkan dan meraikan peserta ini. Walaupun perarakan usungan/tandu masih lagi wujud dan diamalkan, namun tiada dokumentasi formal yang dilakukan untuk mengekalkan dan memperkenalkan amalan ini untuk rujukan pada masa akan datang. 


\section{SOROTAN LITERATUR}

Di sesebuah negeri atau negara yang mempunyai kepelbagaian kaum dan etnik juga mempunyai kepelbagaian dalam aspek budaya dan amalan turun-temurun. Di Sarawak misalnya, masyarakat Melayu pesisir mempunyai suatu amalan unik dan masih diamalkan sehingga kini iaitu upacara perarakan usungan/tandu. Namun, perarakan ini hanya memberi penekanan kepada kanak-kanak yang telah menamatkan pengajian al-Quran. Menurut Hamidah (2013), masyarakat Melayu di Sarawak kaya dengan kepercayaan serta amalan turun-temurun yang menjadi sebahagian daripada peraturan sosial dan dikongsi bersama dalam kehidupan bermasyarakat. Perkara ini mewujudkan rasa ingin tahu pengkaji dan meneroka lagi aspek seni dan adat istiadat yang tidak diketengahkan dalam konteks ilmiah. Upacara perarakan usungan/tandu masyarakat Melayu pesisir Sarawak ini kebiasaannya dilakukan semasa majlis khatam al-Quran yang diurus oleh pihak sekolah.

Amalan ini dikatakan dapat memberi motivasi kepada kanak-kanak untuk terus berjaya. Perkara ini turut dijelaskan oleh Mohamad Haji Arsat (dipetik dalam Hon 1996) yang menyentuh khusus tentang orang Melayu Sarawak sebagai kaum peribumi termaju, mementingkan pendidikan agama dan umumnya anak-anak mendapat pendidikan asas agama dan bahasa. Adat istiadat yang dinyatakan pula menjurus kepada amalan seharian dan dalam upacara tertentu seperti perkahwinan, berpantang, kematian, khatam al-Quran dan sebagainya. Aspek pendidikan agama Islam tidak akan diketepikan, malah upacara perarakan ini telah sinonim dengan majlis khatam al-Quran.

Usungan/tandu pada asalnya merupakan salah satu pengangkutan yang digunakan oleh manusia pada zaman dahulu. Di rantau Asia Tenggara juga terdapat beberapa negara seperti Vietnam, Thailand, Indonesia dan Filipina yang mempunyai usungan/tandu dengan nama-nama yang berbeza mengikut negara.

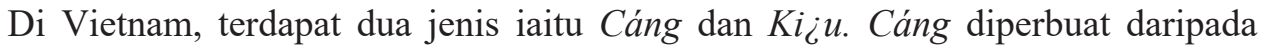
buluh dan penunggang kebiasaannya berbaring. Cáng ini kebiasaannya digunakan untuk mengusung orang sakit. Manakala $K i_{\zeta} u$ adalah lebih terperinci aspek pembuatannya kerana terdapat ukiran-ukiran di bumbung dan di pintu. $K i_{i} u$ juga mempunyai beberapa kerusi untuk penunggang duduk. Setelah mengalami kemajuan dan peredaran zaman, Cáng telah ketinggalan di belakang manakala $K i_{\zeta} u$ terus digunakan oleh masyarakat Vietnam untuk istiadat tradisional dan upacara kesucian kuil. Di Thailand pula, masyarakat Siam memanggil usungan/ tandu sebagai phra wo atau royal sedan yang digunakan untuk upacara besar. 
Royal sedan dihiasi dengan begitu rumit serta rekaan yang sangat cantik dengan penggunaan pelbagai material seperti kaca, ukiran dan warna keemasan. Usungan/ tandu di Thailand hanya digunakan oleh kerabat diraja dan replikanya kini dipamerkan di Muzium Nasional Bangkok.

Jiran serumpun Malaysia, iaitu Indonesia juga mempunyai amalan tradisi yang sama seperti tandu namun lebih dikenali sebagai palanquin atau joli. Bagi masyarakat Jawa, palanquin atau joli merupakan kerusi rotan dengan kanopi yang dilekatkan dua kayu dan dipikul oleh manusia. Ia boleh disewakan kepada sesiapa yang memerlukan perkhidmatan ini. Sebagai penanda status, palanquin yang dihiasi dengan takhta emas pada asalnya hanya untuk kegunaan diraja. Kemudian diteruskan oleh Belanda yang memerintah Indonesia ketika itu sebagai penanda status. Semakin rumit palanquin yang dihasilkan semakin tinggi status pemiliknya. Yusmanto (2016) menyatakan mengikut sejarah, patung Raja Jawa, pangeran, tuan (raden mas) atau bangsawan yang dikenali sebagai jempana diletakkan di atas palanquin sebagai takhta yang dikenali sebagai pangkem. Ia merupakan perarakan tentera besar yang dihiasi warna kekuningan emas sebagai cerminan kepada warna diraja Jawa. Payung emas juga diletakkan di atas palanquin yang dipikul dan diapit oleh pengawal paling setia. Dalam budaya Hindu di Bali hari ini, tradisi menggunakan palanquin untuk patung, senjata atau pusaka diteruskan untuk pemakaman dan ritual yang lebih rumit. Walau bagaimanapun, kegunaan usungan/tandu telah berubah apabila masyarakat biasa juga boleh menggunakannya dalam pelbagai upacara.

Di Selat Nasik, Kabupaten Belitung, Kepulauan Bangka Belitung, Indonesia kerap menggunakan perkataan joli untuk perarakan tandu ini. Menurut Yusmanto (2016) lagi, budaya Melayu di daerah Kecamatan ini masih menggunakan joli untuk menghantar pengantin di majlis perkahwinan. Joli ialah kerusi yang ditandu dan diarak keliling kampung. Sesuai dengan ciri dan kerja harian masyarakat pantai, kerusi yang diikatkan menggunakan kayu dan ditutup dengan sesuatu yang berbentuk ikan. Perkataan "sejoli" diambil berkisahkan saat pengantin lelaki ke rumah pengantin perempuan, si pengantin lelaki ditandu atau diusung dengan joli. Setelah sampai di rumah pengantin perempuan, kedua-duanya ditandu di atas joli, lalu dipanggil sejoli.

Walau bagaimanapun, berlainan pula di persisiran pantai Sarawak iaitu daerah seperti Belawai dan Kabong yang menjadikan amalan perarakan usungan/tandu ini sebagai satu kaedah untuk memuliakan para peserta yang baharu sahaja selesai pengajian al-Quran. Uniknya, amalan ini hanya terdapat di Sarawak dan tidak terdapat di tempat lain. Mereka diraikan di atas usungan/tandu sebagai penghargaan terhadap usaha kerana tekun belajar al-Quran dan mampu menamatkannya. 
Walaupun amalan ini telah diadakan lebih dari 100 tahun yang lalu, tiada makalah dan dokumentasi rasmi dilakukan untuk rujukan generasi akan datang. Perkara ini telah dijelaskan oleh Awang Azman (2010) bahawa budaya kebendaan dalam masyarakat Melayu Sarawak seperti kelong, sirih sole, gendang, rumah Melayu Sarawak, keringkam dan lain-lain lagi yang boleh dikaitkan dengan aspek sosiobudaya masyarakat Sarawak masih lagi kurang dijadikan subjek khusus dalam bidang kajian intensif.

\section{METODOLOGI KAJIAN}

Kajian ini merupakan kajian lapangan yang dibahagikan kepada dua bahagian. Bahagian pertama kajian dilakukan pada 19 hingga 25 November 2018 dan bahagian kedua pula pada 10 hingga 15 Mac 2019. Bahagian pertama dijalankan dengan kajian kes di Kabong, Sarawak semasa perarakan usungan di majlis khatam al-Quran peringkat daerah Kabong. Ia mengambil kira proses penghasilan usungan dan majlis perarakan dilakukan. Kajian lapangan ini dijalankan seperti dalam Jadual 1.

Jadual 1: Bahagian pertama - Kerja lapangan di majlis khatam al-Quran di Kabong, November 2018

\begin{tabular}{ll}
\hline Tarikh & Aktiviti \\
\hline 20 November 2018 & Pemantauan penghasilan usungan di beberapa kampung \\
& di daerah Kabong seperti Kampung Hulu Kabong, \\
& Kampung Hulu Laut Kabong, Kampung Sg. Benang, \\
& Kampung Hulu Darat dan Kampung Hilir. \\
& Penghasilan usungan (cipta-sama) bersama beberapa \\
& keluarga di Kampung Hulu Kabong, Kampung Hulu \\
& Laut Kabong dan Kampung Sg. Benang dan temu ramah. \\
& Dokumentasi video, lakaran dan fotografi majlis khatam \\
& al-Quran di daerah Kabong. \\
\hline
\end{tabular}

Kajian lapangan bahagian pertama dijalankan dengan menggunakan kaedah kajian cipta-sama, pemantauan dan temu ramah. Kaedah cipta-sama digunakan untuk membantu beberapa keluarga di Kabong menghasilkan usungan. Cipta-sama menurut Fronteer (n.d.) ialah kolaborasi pembangunan nilai baharu contohnya konsep, penyelesaian, produk dan perkhidmatan bersama pakar dan pihak yang berkepentingan seperti pelanggan, komuniti, pembekal dan sebagainya. Ciptasama juga merupakan suatu bentuk kolaborasi yang berinovasi apabila buah fikiran 
dikongsikan dan dibangunkan bersama. Sebelum menjalankan kerja lapangan bahagian pertama, beberapa perkara atau permasalahan telah dikenal pasti iaitu:

1. Rekaan usungan perlu direkodkan dan didokumentasikan.

2. Keperluan melukis lakaran awal untuk penghasilan usungan dan temu ramah ringkas bersama kanak-kanak (peserta) tentang keinginan subjek atau usungan yang mereka kehendaki.

3. Beberapa keluarga sangat memerlukan bantuan kewangan untuk menghasilkan usungan.

4. Material yang digunakan untuk menghasilkan usungan sebelum ini tidak praktikal iaitu sangat berat untuk diusung.

5. Amalan usungan ini semakin dilupakan dan memerlukan nilai tambah.

Kaedah cipta-sama digunakan untuk membantu komuniti tersebut dalam penghasilan usungan. Oleh itu, seramai lapan orang pengkaji termasuk pelukis, jurugambar dan juruvideo telah membantu sepuluh keluarga terpilih dalam menyelesaikan perkara-perkara di atas. Bantuan diberikan dalam aspek rekaan, melukis idea awal rekaan termasuk rangka usungan dan lukisan pelbagai sudut dihasilkan untuk memberi gambaran lebih jelas tentang bentuk yang akan dihasilkan. Bantuan juga diberikan dalam aspek dokumentasi pembuatan usungan dari awal sehingga siap untuk simpanan keluarga dan komuniti tersebut. Manakala, kerja lapangan bahagian kedua adalah untuk mendapatkan maklum balas dan refleksi projek selepas majlis khatam al-Quran diadakan di Kabong dan tinjauan serta temu ramah ringkas di beberapa tempat lain seperti dalam Jadual 2.

Jadual 2: Bahagian kedua - Refleksi projek di Kabong, Belawai, Mukah dan Dalat

\begin{tabular}{ll}
\hline Tarikh & Aktiviti \\
\hline 11 Mac 2019 & (Refleksi projek) Temu ramah di beberapa kampung di daerah \\
& Kabong seperti Kampung Hulu Kabong, Kampung Hulu Laut \\
& Kabon dan Kampung Sg. Benang. \\
& (Refleksi projek) Temu ramah ringkas di Kampung Belawai, \\
12 Mac 2019 & Tanjung Manis. \\
13 hingga 14 Mac 2019 & (Refleksi projek) Temu ramah ringkas di Mukah dan Dalat. \\
\hline
\end{tabular}




\section{KAJIAN KES: PERARAKAN USUNGAN MAJLIS KHATAM AL-QURAN DI DAERAH KABONG, SARAWAK}

Secara keseluruhan, kajian ini dilakukan dengan memberi penekanan di daerah Kabong disebabkan komitmen yang tinggi diberikan oleh banyak pihak di daerah ini untuk memulihara dan memartabatkan amalan usungan setiap tahun. Justeru, kajian kes tertumpu di daerah Kabong untuk merekod dan mendokumentasikan penghasilan dan perarakan. Kabong merupakan sebuah daerah kecil yang terletak di bahagian Betong, Sarawak (rujuk Rajah 1). Daerah ini juga terletak di kawasan persisiran Sarawak dan mempunyai majoriti penduduk berketurunan Melayu serta beragama Islam. Penduduk di sini menjadikan perikanan dan pertanian sebagai sumber pendapatan utama serta berniaga secara kecil-kecilan. Setiap tahun, pihak Sekolah Kebangsaan Abang Leman, Kabong akan mengadakan majlis khatam al-Quran untuk murid-murid yang telah menamatkan pengajian al-Quran selepas peperiksaan Ujian Pencapaian Sekolah Rendah (UPSR). Majlis ini menjadi satu kemestian dalam takwim sekolah dan telah diadakan secara turun-temurun. Uniknya, majlis ini dilengkapi dengan perarakan usungan. Namun, amalan usungan ini sangat bergantung kepada penajaan oleh pelbagai pihak terutamanya Ahli Dewan Undangan Negeri (ADUN) N.40 Kabong, Yang Berhormat (YB) Mohd Chee Kadir. Penghasilan setiap usungan menelan perbelanjaan dari RM100 sehingga RM500. Penajaan diperlukan kerana ada sesetengah keluarga yang kurang berkemampuan dari segi kewangan bagi menghasilkan usungan untuk anak-anak mereka. Walau bagaimanapun, menurut YB Mohd Chee Kadir, beliau akan sentiasa menyumbang sama ada dalam bentuk wang ringgit ataupun keringat bagi memastikan amalan unik ini diteruskan agar tidak hilang ditelan zaman. Beliau turut menjelaskan pada tahun 2017, lebih daripada 100 jenis usungan telah dihasilkan semasa Majlis Khatam Perdana peringkat N.40 Kabong. ${ }^{1}$ Majlis Khatam Perdana ini melibatkan hampir kesemua sekolah rendah di kawasan N.40.
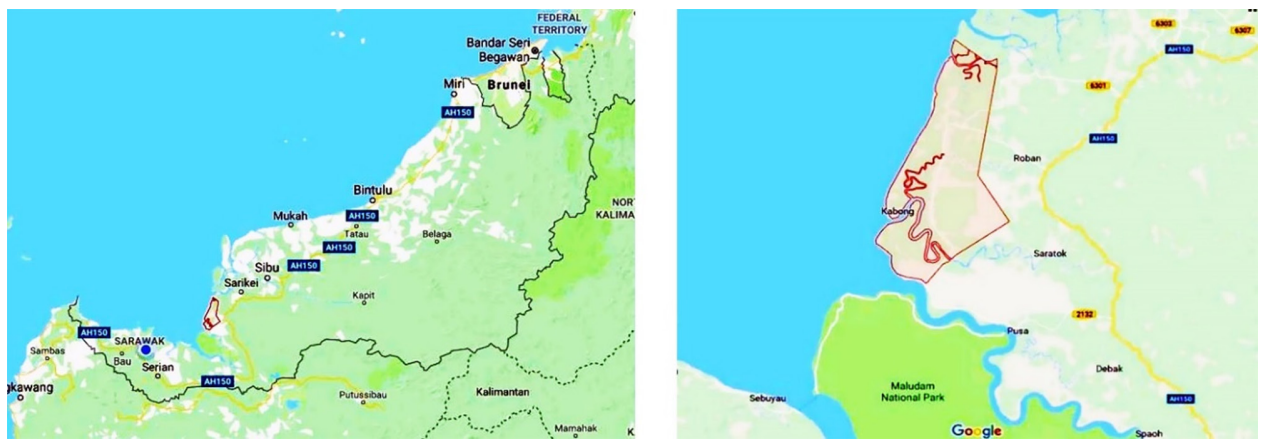

Rajah 1: Peta Kabong, Sarawak.

Sumber: Google Map (n.d.) 
Penduduk Kabong percaya bahawa amalan ini telah wujud lebih dari 100 tahun dahulu yang merupakan amalan turun-temurun peninggalan nenek moyang mereka. Justeru, ada rasa sayang dan keinginan untuk meneruskan amalan ini. Majlis khatam al-Quran yang diadakan pada 24 November 2018 melibatkan seramai 88 orang peserta yang mengambil bahagian. Lebih daripada 20 jenis usungan pelbagai rekaan telah dihasilkan bagi mengusung para peserta dari masjid menuju ke dewan serbaguna diiringi dengan paluan kompang dan hadrah oleh orang kampung. Masjid digunakan sebagai tempat berkumpul semua peserta dan dewan serbaguna digunakan untuk majlis perasmian dan setiap peserta akan membaca surah-surah pilihan. Setiap peserta ataupun keluarga menghasilkan usungan secara sukarela dan tiada paksaan. Sehubungan itu, para peserta yang tidak mempunyai usungan akan berjalan kaki dalam perarakan tersebut.


Rajah 2: Perarakan usungan diiringi dengan paluan kompang dan hadrah (kiri) serta gotong-royong menghasilkan usungan (kanan).

\section{USUNGAN CERMINAN BUDAYA PEMUAFAKATAN, KREATIVITI DAN INOVASI}

Amalan dan praktis usungan ini memperlihatkan kerjasama dan semangat gotong-royong yang tinggi dalam kalangan penduduk Kabong. Puan Lela menyatakan beliau dengan rela hati mengajak dan bekerjasama dengan Puan Ijah menghasilkan usungan untuk kedua-dua anak mereka. ${ }^{2,3}$ Kedua-dua keluarga ini saling bekerjasama dalam menghasilkan usungan tersebut. Semua ahli keluarga turut menyumbang sama ada dari aspek kewangan, tenaga dan buah fikiran dalam menyiapkan usungan tersebut. Bukan itu sahaja, tukang pikul usungan juga masih lagi dipraktikkan secara sukarela. Sehelai sapu tangan akan diberikan kepada setiap seorang tukang pikul sebagai sagu hati atas sumbangan mereka. Setiap usungan akan dipikul oleh empat hingga lapan orang mengikut saiz dan berat usungan tersebut. Berkenaan pemilihan rekaan, mereka bersatu hati memilih masjid sebagai subjek untuk dijadikan inspirasi dalam penghasilan rekaan usungan. 
Proses menyiapkan usungan pula mengambil masa beberapa hari mengikut rekaan, kreativiti dan inovasi perekanya. Walau bagaimanapun, majoriti peserta dan ahli keluarga telah menghasilkan usungan secara individu. Penghasilannya juga dilakukan secara gotong-royong oleh sanak saudara dan rakan-rakan terdekat. Pelbagai rekaan usungan yang dihasilkan memperlihatkan kreativiti dan inovasi masyarakat Melayu pesisir Sarawak ini.

Seharusnya sumber dan kemahiran dalam amalan ini didokumentasikan bagi memulihara dan memartabatkan amalan unik ini agar tidak hilang ditelan zaman dan arus pemodenan serta pembangunan teknologi masa kini. Kebanyakan penghasilan usungan ini tidak berpandukan pada lukisan atau lakaran awal. Penghasilannya yang terus kepada pembuatan bentuk atau usungan itu sendiri menyebabkan tiada dokumentasi berbentuk rekaan dua dimensi yang boleh disimpan dan direkodkan. Lukisan atau rekaan usungan ini adalah sangat penting dan perlu direkodkan agar ia sentiasa ada untuk rujukan pada masa akan datang. Hal ini kerana usungan yang telah digunakan kebiasaannya akan dilupuskan oleh penduduk setempat. Dalam kajian ini, salah satu objektifnya juga adalah untuk merekodkan serta mendokumentasi amalan ini. Justeru, beberapa gambar sekitar majlis dan video perarakan telah diambil sebagai dokumentasi mentah sebelum disunting. Sepertimana yang dikatakan oleh Awang Azman (2010) mengenai pembinaan rumah Melayu Sarawak yang dipengaruhi oleh kepercayaan agama, penghasilan usungan berbeza pengaruhnya kerana ia dihasilkan berdasarkan minat dan kehendak kanak-kanak yang diraikan.

Selain daripada usungan, terdapat juga suatu "arca/replika" menyerupai usungan namun saiznya agak kecil. Ia dipanggil "jong" (Rajah 3) dan dipikul oleh kanak-kanak lain (bukan peserta khatam al-Quran) semasa perarakan usungan. Perkataan jong digunakan oleh masyarakat Melayu di Kabong yang merujuk kepada sampan atau bot. Fungsinya adalah untuk membawa pulut kuning dan bunga telur sebagai hadiah kepada guru yang mengajar al-Quran oleh peserta yang diraikan. Terdapat juga para peserta yang memberikan duit sebagai hadiah kepada guru. Selepas tamatnya majlis khatam al-Quran, kanak-kanak ini akan memikul jong ke rumah guru tersebut dan memberikan pulut kuning serta bunga telur. Jong akan dikembalikan semula kepada tuan rumah atau bapa peserta. Ia simbolik ucapan penghargaan atau terima kasih kepada seorang guru. Pak Sudin menyatakan bahawa jong yang digunakan oleh salah seorang peserta ialah kepunyaan beliau yang setiap tahun akan dipinjam oleh peserta lain. ${ }^{4}$ Beliau menyatakan bahawa jong tersebut (Rajah 3) telah berusia lebih daripada 20 tahun. Jong tersebut telah digunakan secara turun-temurun oleh keluarga dan sanak saudara terdekat. Walau bagaimanapun, perarakan jong ini semakin berkurangan atas beberapa faktor seperti kerosakan jong yang digunakan hampir setiap tahun, 


\section{Mohamad Faizuan Mat}

hadiah kepada guru terus dihantar ke rumah tanpa mengikut perarakan, kekurangan tukang kayu yang pakar dalam menghasilkan jong dan kos penghasilan yang tinggi. Penghasilan jong melibatkan kos yang tinggi sekiranya pemilik memilih kayu/papan yang baik dan tahan lama. Pak Sudin turut menyatakan bahawa kos penghasilan setiap jong adalah lebih kurang RM500 hingga RM1,000 bergantung pada material yang digunakan.

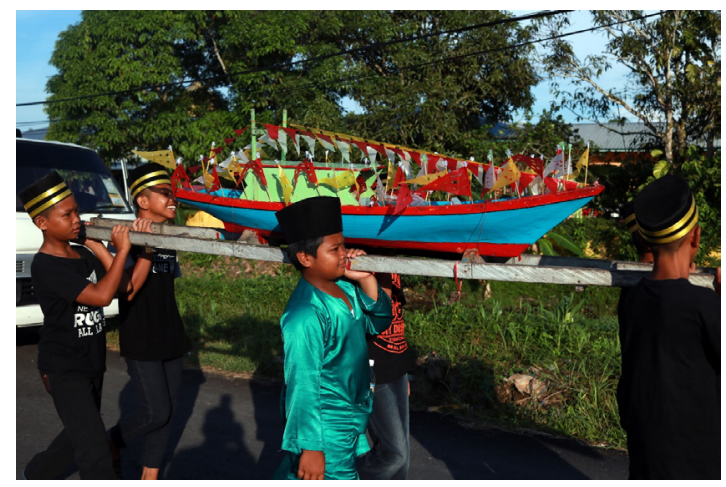

Rajah 3: Contoh jong diperarakan majlis khatam al-Quran.

Subjek seperti sampan dan ikan yu (Rajah 4) kerap digunakan sebagai inspirasi bagi menghasilkan rekaan usungan. Merujuk kepada faktor geografi dan kehidupan seharian di Kabong misalnya, majoriti penduduk bekerja sebagai nelayan sebagai sumber pendapatan utama. Usungan seperti Rajah 4 merupakan contoh usungan semasa berlangsungnya majlis khatam al-Quran peringkat daerah Kabong pada tahun 2017. Sehubungan itu, dapat diinterpretasikan bahawa subjek utama dalam penghasilan rekaan usungan terinspirasi daripada perkara yang sangat dekat dengan diri serta paling tepat ialah pekerjaan mereka (ibu bapa peserta).
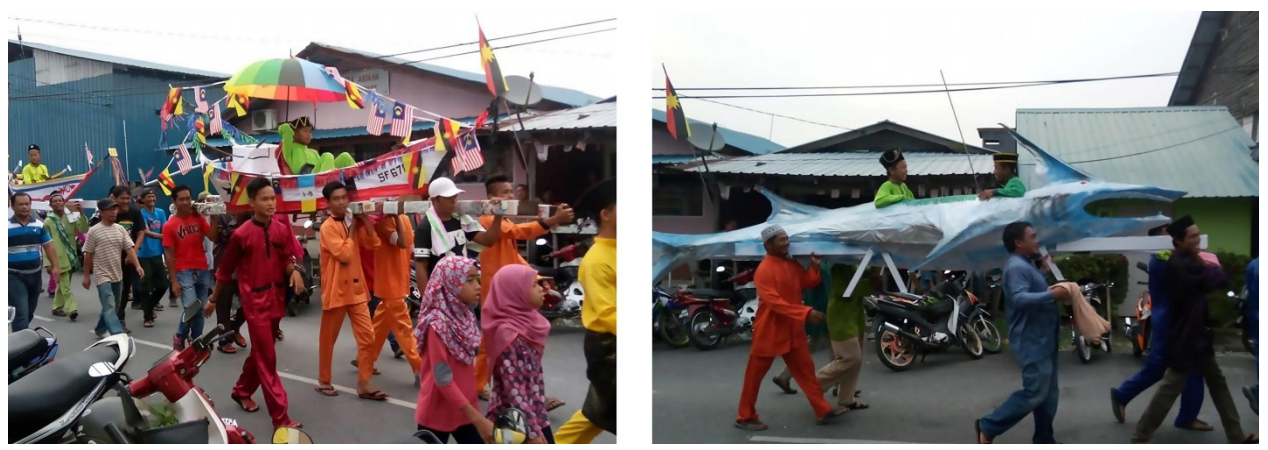

Rajah 4: Usungan yang berbentuk sampan (kiri) dan ikan yu (kanan). 
Namun, aspek kreativiti dan imaginasi turut tidak ketinggalan dalam penghasilan usungan ini. Kreativiti dan imaginasi ini tercetus apabila si cilik yang diraikan di atas usungan mempunyai kesempatan untuk membuat permintaan ke atas rekaan yang akan dihasilkan. Rekaan berbentuk kapal terbang seperti Rajah 5 (kiri) ialah permintaan kanak-kanak yang bercita-cita menjadi juruterbang. Begitu juga dengan rekaan jet pejuang seperti Rajah 5 (kanan). Ia merupakan permintaan yang membawa kepada refleksi cita-cita kanak-kanak tersebut yang ingin menjadi tentera udara. Ibu bapa dan ahli keluarga akan berusaha menghasilkan usungan berbentuk kapal terbang dan jet pejuang bagi memenuhi permintaan anak-anak mereka. Beberapa lakaran usungan dihasilkan semasa kajian lapangan berdasarkan kepada subjek atau imej yang diingini oleh peserta perarakan. Lakaran tersebut diterjemahkan oleh ibu bapa dan keluarga kepada objek sebenar usungan dalam bentuk 3 dimensi. Lakaran ini menggambarkan kreativiti, inovasi dan imaginasi masyarakat pesisir ini.
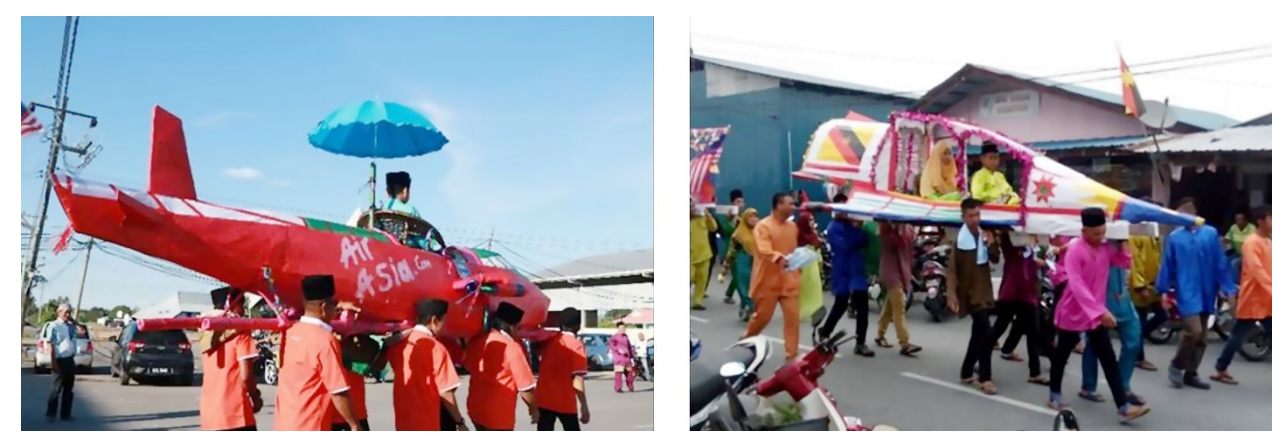

Rajah 5: Usungan yang berbentuk kapal terbang (kiri, 2018) dan jet pejuang (kanan, 2017).

Rekaan usungan berbentuk Irrawady dolphin seperti Rajah 6 (kiri) dijadikan inspirasi kerana ikan tersebut banyak terdapat di perairan pesisir Sarawak. Rekaan ini menunjukkan bahawa subjek yang dipilih datang daripada aspek geografikal dan ekologi tempat tersebut. Pemilihan subjek untuk dijadikan rekaan usungan ini mempamerkan daya kreativiti dan inovasi. Rekaan mutiara pada Rajah 6 (kanan) dipilih sebagai metafora kepada sesuatu yang berharga dan memperlihatkan pemahaman dan kebijaksanaan masyarakat pesisir. Kanak-kanak yang diraikan dianggap sebagai sesuatu yang berharga kerana telah berjaya menamatkan pengajian mereka dengan cemerlang. Justeru, pemilihan mutiara sebagai cerminan atau metafora perlambangan kepada sesuatu yang berharga adalah sangat tepat. 

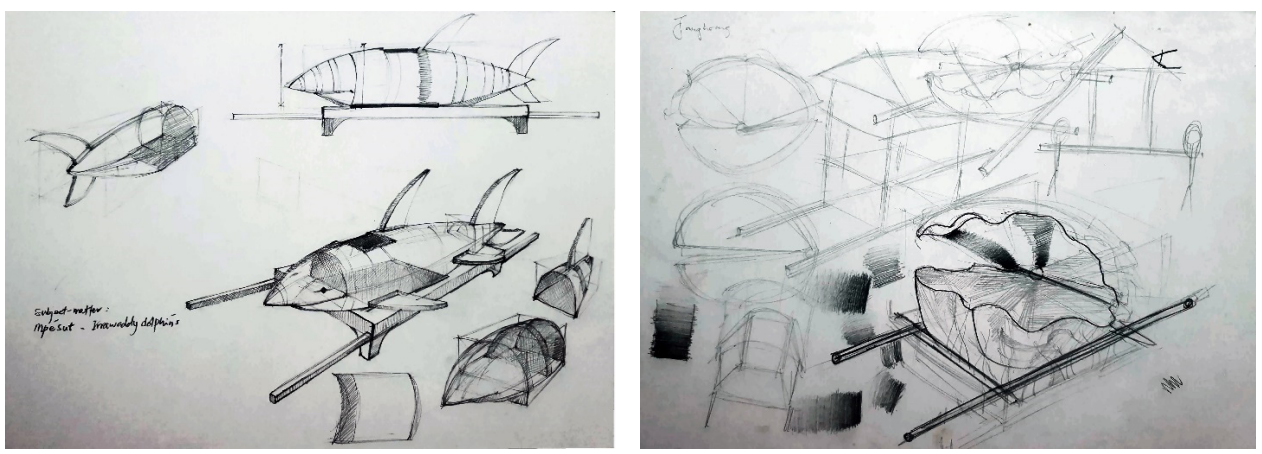

Rajah 6: Usungan berbentuk Irrawady dolphin (kiri) dan mutiara (kanan).

Merujuk kepada lakaran berbentuk burung kenyalang (Rajah 7, kiri), masyarakat pesisir Sarawak sedar akan kepentingan menyerlahkan ikonografi negeri mereka. Manakala lakaran berbentuk naga pada Rajah 7 (kanan) menunjukkan mereka juga tidak ketinggalan dalam menggunakan imaginasi sebagai inspirasi utama penghasilan rekaan usungan. Subjek naga yang dipilih tidak memberi maksud tertentu, sebaliknya hanya cetusan inspirasi daripada imaginasi dan keinginan kanak-kanak yang diraikan.


Rajah 7: Lakaran usungan berbentuk burung kenyalang (kiri) dan naga (kanan).

Setiap keinginan dan permintaan anak-anak ditunaikan sebagai suatu hadiah kepada mereka kerana telah menamatkan pengajian al-Quran. Tambahan pula, ada anak-anak yang berjanji akan terus berusaha mencapai kejayaan dalam persekolahan atau dalam apa jua bidang yang akan mereka ceburi. Amalan perarakan usungan ini sangat bernilai dalam diri anak-anak dan keluarga serta komuniti setempat kerana ia sebagai suatu usaha murni dalam membentuk motivasi diri dan kecenderungan untuk terus berjaya dalam kehidupan di dunia mahupun di akhirat. 


\section{AMALAN PERARAKAN USUNGAN}

Kajian yang dilakukan mendapati bukan hanya di Kabong sahaja, perarakan ini juga masih lagi diamalkan dan dijalankan di beberapa kawasan persisiran Sarawak yang lain seperti Belawai, Tanjung Manis, Mukah, Daro, Simunjan dan Bintulu. Oleh yang demikian, nama-nama untuk usungan ini berbeza mengikut tempat. Contohnya, di bahagian Mukah dan Daro, penduduk setempat mengenali usungan ini sebagai tandu. Faktor ini dipengaruhi juga oleh perbezaan kaum kerana majoriti penduduk di Mukah dan Daro berketurunan Melanau dan beragama Islam. Sementara di Kabong pula, majoriti berketurunan Melayu. Tidak dinafikan, sebutan-sebutan ini berlainan disebabkan oleh faktor bahasa dan lain-lain. Jika dilihat dari sudut rekaan pula, tidak banyak perbezaan yang ketara. Walaupun kegiatan harian penduduk atau komuniti mempengaruhi rekaan tersebut, fungsi usungan atau tandu ini masih lagi mempunyai objektif yang sama iaitu meraikan pelajar-pelajar di majlis khatam al-Quran.

\section{Daerah-daerah yang Masih Mengamalkan Perarakan Usungan/Tandu}

Sehingga ke hari ini, amalan perarakan usungan/tandu ini masih lagi aktif di kawasan pesisiran Sarawak. Namun, ia telah pupus di perkampungan ataupun daerah yang berdekatan pusat bandar. Antara kawasan yang masih lagi giat dalam meneruskan amalan ini ialah Kabong; Belawai, Tanjung Manis; Mukah dan Dalat; dan Bintulu.

\section{Contoh Usungan/Tandu yang Pernah Digunakan oleh Penduduk-penduduk di Majlis Khatam al-Quran Selain dari Daerah Kabong}

Rajah 8 menunjukkan contoh usungan/tandu yang telah digunakan oleh penduduk di kawasan Belawai, Tanjung Manis. Penghasilannya juga dipengaruhi oleh aktiviti setempat dan pekerjaan serta tiada perbezaan yang ketara dengan usungan/tandu di daerah lain. Contohnya, usungan/tandu berbentuk jentolak (Rajah 8, kanan) merupakan kegunaan penduduk dalam aktiviti pertanian. Dari aspek kreativiti dan inovasi, daerah Belawai tampak lebih berani dalam menonjolkan rekaan-rekaan yang radikal dan kontemporari berbanding daerah lain. 

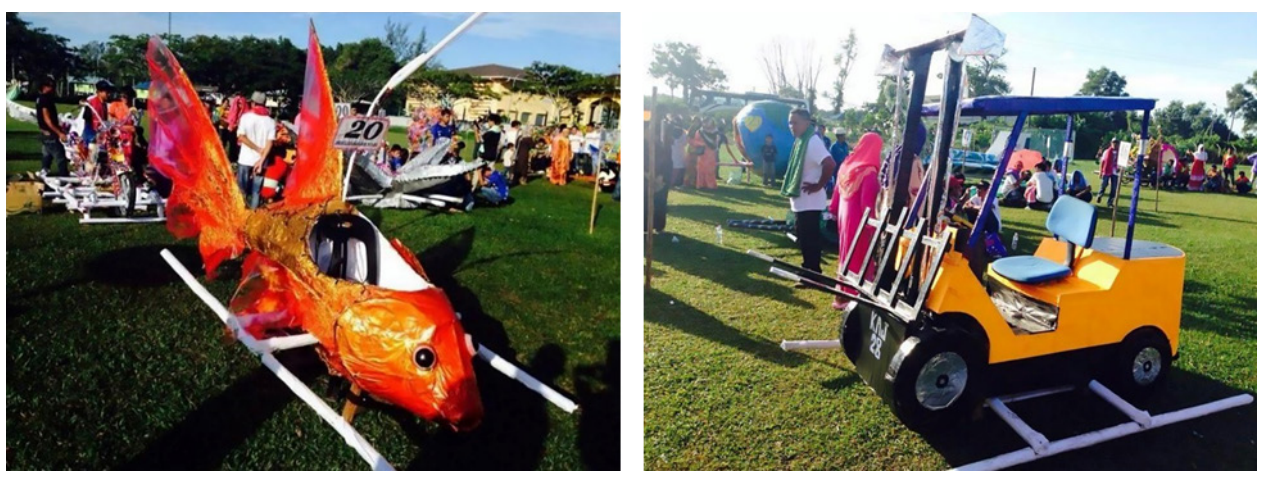

Rajah 8: Contoh jenis-jenis usungan/tandu di kawasan Belawai, Tanjung Manis.

Sumber: RTM Sarawak (2014)

Berbeza pula di kawasan Bintulu, amalan ini telah mengalami perubahan dari aspek pelaksanaan dan rekaan. Perarakan usungan/tandu ini diadakan pada sebelah malam kerana rekaannya dihasilkan dengan menggunakan diod pemancar cahaya untuk memberikan kesan cahaya dan membuatkan perarakan ini tampak sangat meriah, terang benderang dan berwarna-warni oleh diod pemancar cahaya yang didatangkan dengan pelbagai warna. Terdapat sedikit perbezaan di Bintulu kerana amalan ini diadakan pada waktu malam dan konsep rekaan pula mempunyai sentuhan moden (Rajah 9).

Konsep dan objektif amalan ini masih sama di kesemua tempat iaitu meraikan kejayaan anak-anak di majlis khatam al-Quran walaupun terdapat perbezaan pada rekaan, waktu dan masa. Namun begitu, terdapat juga sebahagian kampung atau daerah yang mengadakan pertandingan penghasilan usungan dan perarakan membawa orang dewasa atas dasar kemuafakatan dan dijadikan sebagai aktiviti untuk berhibur atau beriadah. Aktiviti atau amalan ini tidak terikat di majlis khatam al-Quran bahkan juga boleh diadakan di majlis perkahwinan atau apa jua keraian. Majlis khatam al-Quran dan perarakan usungan telah sebati dan dilaksanakan setiap tahun semasa cuti sekolah dan sekolah merupakan nadi utama yang mengurus dan menggerakkan amalan ini. 

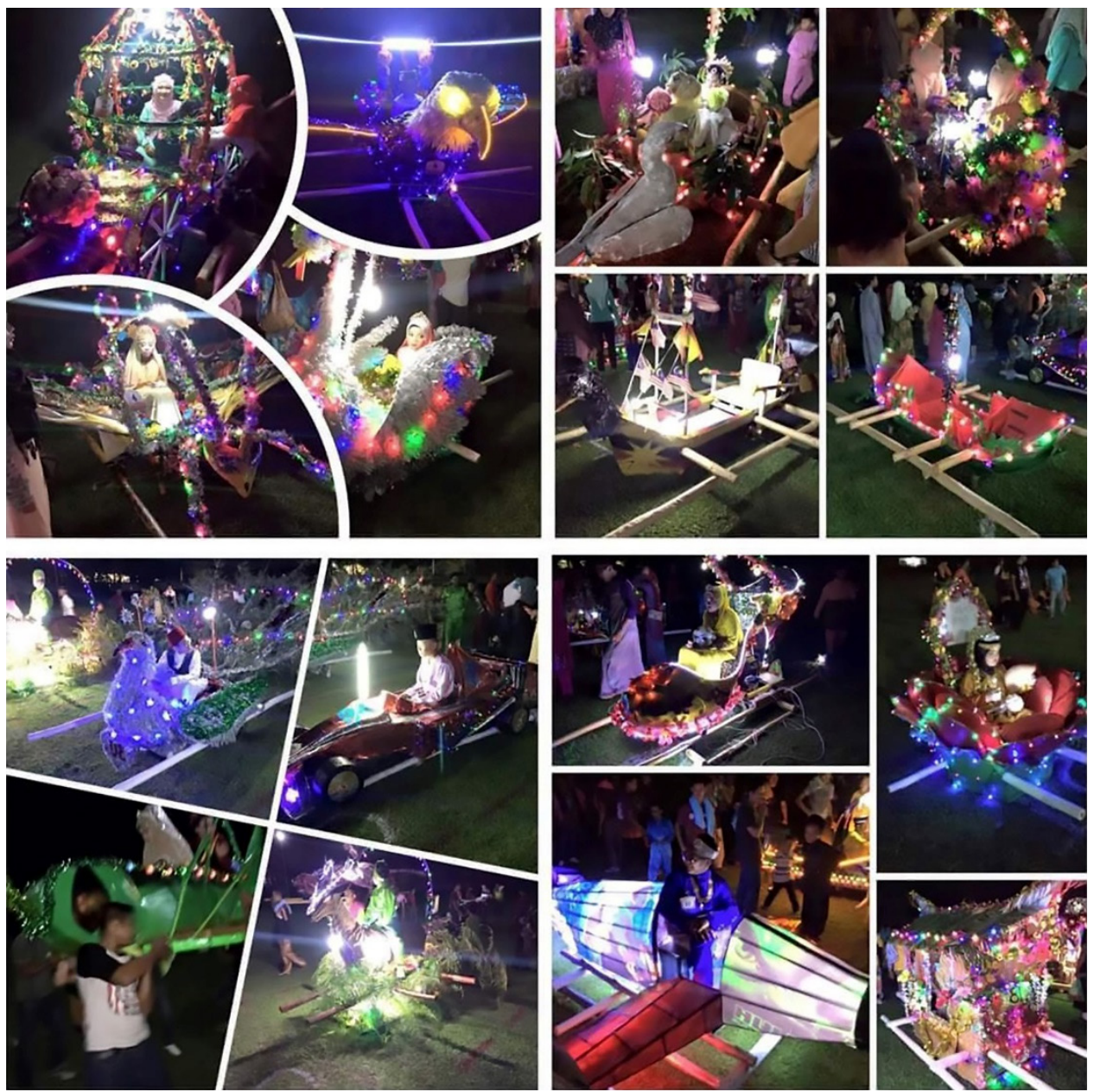

Rajah 9: Jenis usungan/tandu di kawasan Bintulu. Sumber: Bintulu Info (2015)

\section{DAPATAN KAJIAN}

Menurut YB Mohd Chee Kadir terdapat perbezaan antara usungan dan tandu. ${ }^{1}$ Usungan dipikul (diletakkan di atas bahu) manakala tandu pula diangkat sehingga ke paras pinggang oleh orang yang membawanya. Namun begitu, tiada kaedah mengangkat sehingga ke paras pinggang semasa perarakan khatam al-Quran di kawasan pesisir Sarawak. Semua kawasan persisiran yang mengamalkan amalan perarakan khatam al-Quran ini mengusung replika usungan di atas bahu mereka. 
Menurut beliau lagi, dalam aspek pemeliharaan amalan ini, amalan perarakan usungan berkemungkinan akan dilupakan oleh generasi muda sekiranya tiada pihak yang membantu dalam penyediaan dana dan tenaga. Oleh itu, amalan ini harus dikekalkan dan dipelihara. Antara daerah yang masih lagi giat menghidupkan amalan unik ini seperti Kabong, Belawai, Mukah, Dalat dan sekitar bandar Bintulu kerana terdapat wakil rakyat yang sedar akan nilai tradisi dan sanggup menyumbang ke arah kelestariannya. Seperti di kebanyakan tempat tersebut, kebergantungan amalan ini datang daripada pihak pengurusan sekolah rendah yang merupakan tunjang utama amalan ini. Seperti di Kabong, Sekolah Kebangsaan Abang Leman Kabong merupakan pihak yang bertanggungjawab dalam menguruskan dan melaksanakan majlis khatam al-Quran selepas peperiksaan UPSR dijalankan.

Selain itu, wakil rakyat juga memainkan peranan penting supaya amalan ini dapat dilestarikan. Kebanyakan keluarga peserta tidak akan turut serta dalam amalan ini sekiranya tiada peruntukan kewangan yang diberikan oleh wakil rakyat mereka. Contohnya, pada tahun 2017 di Kabong, YB Mohd Chee Kadir memperuntukkan sebanyak RM100 untuk setiap keluarga peserta bagi menyediakan material dalam menghasilkan usungan mereka. Pada tahun 2017, di Kabong sahaja hampir 30 peserta mengikuti perarakan usungan ini di Majlis Khatam al-Quran Perdana peringkat N.40 Kabong.

Amalan ini juga telah diberi nilai tambah oleh sekumpulan pelukis di Sarawak. Pada 15 Februari 2019 hingga 1 Mac 2019, sebuah pameran seni visual diadakan di Saradise Gallery, Kuching yang memberi penekanan kepada dokumentasi rekaan usungan dan amalannya. Pameran yang bertajuk Usungan: A Presentation of Innovation and Artistic Creation in Bonded Community, Kabong yang dirasmikan oleh Datuk Abdul Karim Rahman Hamzah, Menteri Pelancongan, Kesenian, Kebudayaan, Belia dan Sukan, Sarawak telah mempamerkan lebih daripada 30 karya seni berbentuk catan, lukisan, fotografi, arca dan video (Rajah 10). Seramai lapan orang artis tempatan telah terlibat dalam pameran ini. Menurut Zarina (2019), objektif pameran ini adalah untuk mempromosi, merekod dan mendokumentasi usungan kerana tiada rekod yang dibuat sebelum ini. Setiap kali selepas tamatnya majlis khatam al-Quran, penduduk atau pemilik akan melupuskan usungan tersebut atas beberapa faktor yang tidak dapat dielakkan seperti ruang penyimpanan, ketidaktahanan cuaca dan sebagainya. 


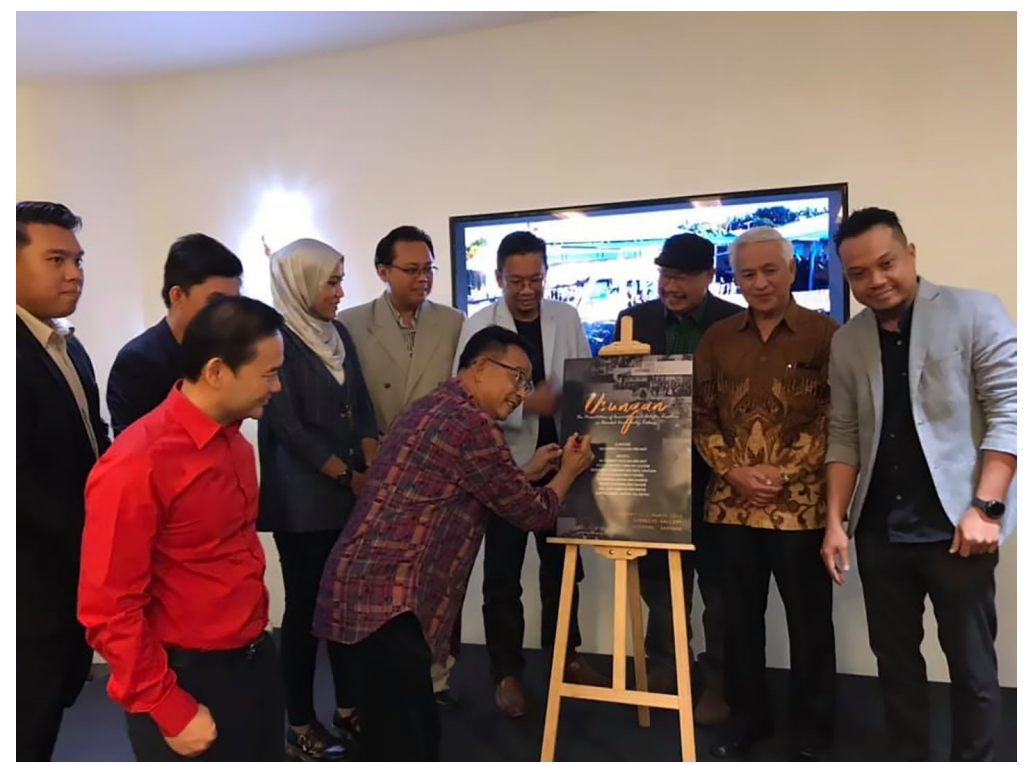

Rajah 10: Majlis perasmian pameran Usungan: A Presentation of Innovation and Artistic Creation in Bonded Community, Kabong, 2019. Sumber: Datuk Abdul Karim Rahman Hamzah (2019b)

Usaha membawa dan mengetengahkan amalan usungan ke ruang galeri mengangkat martabat amalan ini dan meningkatkan kesedaran dalam kalangan komuniti bandar. Hasil daripada pameran ini didapati bukan hanya masyarakat semenanjung yang kurang sedar kewujudan budaya ini, malah penduduk sekitar Kuching juga baharu menyedari akan wujudnya amalan unik sebegini. Datuk Abdul Karim Rahman Hamzah (2019a) menyatakan bahawa amalan ini telah wujud sejak sekian lama di Sarawak namun baharu kali ini beliau melihat ada usaha untuk memperkenalkan, menaikkan dan mendokumentasikan amalan usungan/tandu ini. Tambah beliau lagi, usaha sebegini amat penting agar budaya dan seni yang ada daripada pelbagai kaum dan etnik di Sarawak dapat dipelihara serta menjadi warisan kepada generasi masa hadapan. Pameran ini juga telah menjadi titik tolak kepada penyelidik dan penggiat yang memperjuangkan dan mengangkat budaya setempat apabila Datuk Abdul Karim Abdul Rahman Hamzah menyatakan yang beliau akan terus komited memberi peruntukan kepada institusi pengajian tinggi (IPT) yang berminat dalam menjalankan penyelidikan seni dan budaya berkaitan Sarawak.

Tidak cukup dengan pameran, pelukis-pelukis ini juga telah menyertai pertandingan "Sarawak More to Discover Indie Video Competition" anjuran Sarawak Tourism Federation (Mohamad Faizuan 2019) dan telah mendapat hadiah sagu hati dengan penyertaan video pendek berkisarkan amalan usungan 
(Rajah 11). Dua penyelidik juga telah berjaya ke peringkat akhir pertandingan serta pameran Bakat Muda Sezaman 2019 yang telah diadakan bermula April hingga September 2019. Pertandingan dan pameran ini dianjurkan oleh Balai Seni Negara dengan tujuan mencari bakat seniman muda baharu dan subjeksubjek terkini. Penyertaan dua penyelidik ini dalam Bakat Muda Sezaman 2019 mempunyai objektif yang sama iaitu memperkenalkan dan memartabatkan amalan usungan ke ruang kontemporari galeri bersifat kebangsaan. Hasil daripada pameran dan pertandingan ini, amalan usungan telah diperkenalkan seterusnya didokumentasikan dan diterbitkan menjadi satu bab dalam buku terbitan Balai Seni Negara. Jelas sekali, penerimaan komuniti luar mahupun bandar terhadap amalan usungan ini sangat memberansangkan. Justeru, amalan ini sedikit sebanyak telah dikenali dan ditunggu-tunggu pelaksanaannya setiap tahun di Sarawak.



Rajah 11: Majlis penyampaian hadiah pertandingan "Sarawak More to Discover Indie Video Competition 2019".

Pertandingan Bakat Muda Sezaman 2019 ialah pertandingan seni visual tertua di Asia Tenggara yang berprestij dan dikenali ramai. Pertandingan ini merupakan landasan terbaik bagi memperkenalkan amalan usungan/tandu pada peringkat kebangsaan dan antarabangsa. The Parade of the Usungan telah terpilih ke peringkat akhir daripada lebih 100 penyertaan. Salah seorang juri pertandingan tersebut Dr. John Xavier (2019) dari Kochi, India meletakkan The Parade of the Usungan dalam kelompok 10 terbaik daripada 44 pilihan penyertaan akhir 
(Rajah 12). Ternyata amalan usungan ini mampu menarik minat juri dari luar negara. Hasil penyelidikan mendapati kebanyakan warga di Semenanjung masih belum menyedari akan kewujudan amalan sebegini. Justeru, ia bagai satu kejayaan kepada kumpulan penyelidik dan peserta Bakat Muda Sezaman 2019 dalam mengetengahkan dan menambah nilai pada amalan ini.


Rajah 12: The Parade of the Usungan di Pertandingan Bakat Muda Sezaman 2019.

\section{KESIMPULAN}

Amalan usungan/tandu di majlis khatam al-Quran di kawasan pesisir Sarawak ini amat baik untuk diteruskan. Keunikan amalan ini tidak terdapat di tempat lain dan harus dikekalkan untuk tatapan serta kebanggaan generasi akan datang. Amalan usungan ini datangnya dari majlis khatam al-Quran, bermakna tujuan utamanya adalah untuk melahirkan generasi Muslim yang celik al-Quran sekali gus membudayakan amalan membaca al-Quran terutamanya generasi muda. Amalan usungan pula dilihat sebagai motivasi dan hadiah untuk anak-anak 
yang telah menamatkan pengajian al-Quran serta peperiksaan. Pujian harus diberikan kepada pihak sekolah kerana terus komited menguruskan majlis khatam al-Quran, sekali gus melaksanakan amalan perarakan usungan ini. Wakil rakyat juga mempunyai peranan yang sangat penting dalam menyalurkan dana dan keringat untuk terus memperjuangkan amalan ini agar tidak dipinggirkan.

Hasil daripada penyelidikan ini, beberapa perkara boleh dicontohi daripada amalan perarakan usungan. Pertama ialah nilai permuafakatan dan kerjasama kejiranan yang sangat utuh dalam masyarakat pesisir Sarawak. Perkara ini dilihat begitu menonjol sekali apabila mereka bekerjasama dalam menyiapkan arca/ replika usungan, yang kemudiannya diusung mengelilingi kampung oleh jiran tetangga dan saudara-mara secara sukarela untuk meraikan anak-anak tersebut. Kedua, semangat dan kecekalan komuniti pesisir Sarawak ini dalam mengekalkan amalan atau budaya yang mereka sedari sangat berharga dan unik untuk diteruskan. Hal ini dibuktikan dengan rekaan usungan yang diperbuat daripada bahanbahan semula jadi dan kitar semula yang tidak memerlukan wang ringgit bagi keluarga yang tidak berkemampuan. Ketiga, elemen kreativiti dan inovasi dalam masyarakat pesisir Sarawak telah wujud sejak sekian lama. Pelbagai rekaan usungan yang sangat cantik dan unik telah dihasilkan. Akhir sekali, ia menjadi satu keperluan untuk kita melestarikan dan memartabatkan amalan serta budaya yang ada dalam masyarakat tempatan. Amalan perarakan usungan/tandu oleh masyarakat pesisir Sarawak perlu dikekalkan dan dibantu agar dapat diteruskan oleh generasi muda pada masa akan datang kerana amalan, tradisi dan budaya yang sangat unik ini tidak terdapat di mana-mana negeri lain di Malaysia.

Kerajaan negeri Sarawak harus melihat amalan ini sebagai satu khazanah dan objek budaya yang sangat berharga. Justeru, pihak kementerian yang berkaitan di Sarawak perlu bertindak untuk menyediakan dana dan geran bagi penyelidikan ini. Hasil kajian mendapati bahawa amalan ini pernah dilakukan di Kuching pada suatu ketika dahulu dan pernah diamalkan bukan saja oleh masyarakat pesisir Sarawak, bahkan keseluruhan masyarakat Melayu peribumi Sarawak. Amalan ini tidak dilestarikan sepenuhnya dan hanya masyarakat pesisir sahaja yang komited untuk memelihara amalan ini. Faktor-faktor ini disebabkan oleh urbanisasi dan pembangunan sesebuah tempat dan akhirnya amalan sebegini hilang dan lupus begitu sahaja. Sudah tiba masanya kerajaan Sarawak atau Malaysia secara keseluruhannya mengangkat martabat amalan ini. 


\section{NOTA}

1. Temu ramah bersama YB Mohd Chee Kadir, Wakil Rakyat Daerah Kabong N.40, 14 November 2018 di Pusat Khidmat Komuniti N.40 Kabong, Sarawak.

2. Temu ramah bersama Puan Lela, Kampung Hulu Laut Kabong, Kabong, 12 November 2018.

3. Temu ramah bersama Puan Ijah, Kampung Sungai Benang, Kabong, 13 November 2018.

4. Temu ramah bersama Pak Sudin, Kampung Hilir Laut, Kabong, 13 November 2018.

\section{RUJUKAN}

Awang Azman Awang Pawi. 2010. Sarawak Malay material culture and their weltanschauung: Some preliminary research themes and findings. The 2nd International Conference on Humanities and Social Sciences, Faculty of Liberal Arts, Prince of Songkla University. 10 April.

Bintulu Info. 2015. Tandu berhias sempena majlis khatam al-Quran di Belawai. https://www.facebook.com/BintuluInfoFromBintuluWithLove/posts/acara -tandu-berhias-malam-tadi-sempena-majlis-khatam-al-quran-di-belawaicantik -k/1074259249285377/ (accessed January 2019)

Datuk Abdul Karim Rahman Hamzah. 2019a. Ucapan perasmian pameran usungan: A presentation of innovation and artistic creation in bonded community, Kabong, Saradise Gallery, Kuching, Sarawak. 15 February.

2019b. Majlis perasmian pameran usungan: A presentation of innovation and artistic creation in bonded community, Kabong, 2019 (Facebook). https://www.facebook.com/YBKarimHamzah/photos/pcb.1593394590791877/ 1593394094125260/?type=3\&theater (accessed 16 February 2019).

Google Map. n.d. Kabong, Sarawak. https://www.google.com/maps/place/Kabong, +Sarawak/@1.8798776,111.0420756,11z/data=!3m1!4b1!4m5!3m4!1s 0x31f98771f9b647e3:0xebb2f9117ad3d3e6!8m2!3d1.8040279!4d111.1190129 (accessed May 2019).

Hamidah Abdul Wahab. 2013. Petua dan pantang larang tradisional dalam alam Melayu Sarawak. International Journal of the Malay World and Civilisation 1(1): 89-97.

Hon, K.F. 1996. Sejarah perkembangan Lembangan Rajang di Sarawak. Sarawak: Jawatankuasa Warisan Kebudayaan Dewan Suarah.

Mohamad Faizuan Mat. 2019. Discover Sarawak through the march of the usungan (YouTube). 17 August. https://www.youtube.com/watch?v=nX1-I9-nGX0 (accessed 17 August 2019).

RTM Sarawak. 2014. Perarakan tandu berhias khatamal al-Quran Belawai. 25 October. https://www.facebook.com/RTM.Sarawak/posts/751301991601871\%20/ (accessed January 2019). 
The Fronteer. n.d. What is co-creation? A definition, some background and how it's done. https://fronteer.com/what-is-co-creation/ (accessed December 2019).

Xavier, J. 2019. Bakat muda sezaman young contemporaries open + lab. Kuala Lumpur: Balai Seni Negara.

Yusmanto, E., ed. 2016. Penggunaan joli untuk pengantin masih dipertahankan masyarakat Selat Nasik. Posbelitung.co. 24 April. https://belitung.tribunnews. com/2016/04/24/penggunaan-joli-untuk-pengantin-masih-dipertahankanmasyarakat-selat-nasik (accessed January 2019).

Zarina Abdullah. 2019. FSGK UNIMAS lancar pameran ‘usungan’. Mingguan Sarawak. 17 February. 